\title{
1 Experimental correlations and CFD model of a non-tubular 2 heater for a Stirling solar engine micro-cogeneration unit
}

\author{
David García ${ }^{1}$, María-José Suárez ${ }^{1}$, Eduardo Blanco ${ }^{1}$ and Jesús-Ignacio Prieto ${ }^{1, *}$ \\ 1 University of Oviedo, Spain \\ * Correspondence: jprieto@uniovi.es; Tel.: +34-98-518-2081
}

\begin{abstract}
A non-tubular heat exchanger for use in a Stirling solar engine micro-CHP unit is being developed by the University of Oviedo and the technological research centre IK4-Tekniker Foundation. In this article, the correlations for the friction factor and Stanton number previously obtained under steady flow conditions are revised and the corresponding experimental data are used to validate a CFD model of the heater. The CFD model enables the estimation of variables whose measurement is practically unviable, as is the case for the spatial distribution of wall and gas temperatures. The conceptual importance of the heater wall temperature for the analysis and design of Stirling engines is highlighted, and some limitations that are inherent in the non-tubular geometry are observed. The CFD model provides a basis for the analysis of engine operation and for subsequent geometric optimization of the heater. To evaluate the engine power and efficiency forecasts under nominal operating conditions, the CFD model is used to complement the analysis procedure based on experimental data from benchmark engines with very different geometries and operating variables. The results predict that the engine will be able to exceed the targets set in the preliminary design stage.
\end{abstract}

Keywords: Stirling engine, non-tubular heater, correlations, CFD model, similarity, performance characteristics.

\section{Introduction}

One of the goals in the world's energy scenario is the development of smart grids and distributed generation systems based on renewable sources. In this context, Stirling engines are among the alternatives that have a relevant role [1-7], as they can operate as combined heat and power units using alternative fuels or even solar energy [8].

Usually heat exchangers in Stirling engines are composed of tubes, which have proved their feasibility for combustion applications. However, when solar energy is proposed as the energy source, the relevant heat transfer mechanism is radiation instead of convection. For this application, reducing shadows between tubes is a common design problem, as they make it difficult to achieve a uniform wall temperature and contribute to decrease the effective absorbent surface of the receiver. Therefore, it is interesting to think about heat exchangers with different geometries, specially adapted to solar radiation heat transfer.

The University of Oviedo and the technological research centre IK4-Tekniker Foundation have developed a Stirling solar micro power unit, designed using similarity criteria previously introduced by independent authors. The scaling of indicated power has been justified by detailed analyses of the physical and geometric variables influencing the thermodynamic performance of the gas circuit [9-15], while the analysis of mechanical losses has allowed this procedure to be extended for brake power scaling [16-18]. The approach is based not only on experimental data but also on theoretical concepts and has proven its usefulness both for analysis and design purposes [19-25].

The Philips M102C engine has been selected as the reference prototype for scaling, but it is noted that some similarity criteria were relaxed to obtain a more compact model, a thermodynamic mid-plane closer to the regenerator's middle section and a non-tubular heater more suitable for the conversion of solar energy. This non-tubular heater has been tested under steady flow conditions 
and both friction and heat transfer experimental correlations have been obtained [26] to compare its performance with that corresponding to an equivalent tubular heater.

The tests have provided data that can also be used to validate a computational fluid dynamic (CFD) model, with the objective of extending the range of correlations until the Reynolds number values correspond to the velocities expected in the engine operation, as well as to establish the basis for subsequent optimization of the new geometry.

In this article, we review the previously proposed correlations and analyse the results of the numerical simulations performed with the CFD model of the non-tubular heater. Likewise, engine performance expectations are deduced from the combination of those results and correlations previously obtained from the experimental data of benchmark Stirling engines, so the article can also be seen as an example of preliminary design through a combination of procedures.

\section{Revision of experimental correlations of the non-tubular heater}

The non-tubular heater is part of an experimental alpha type Stirling engine with Ross-yoke drive mechanism (Figure 1).

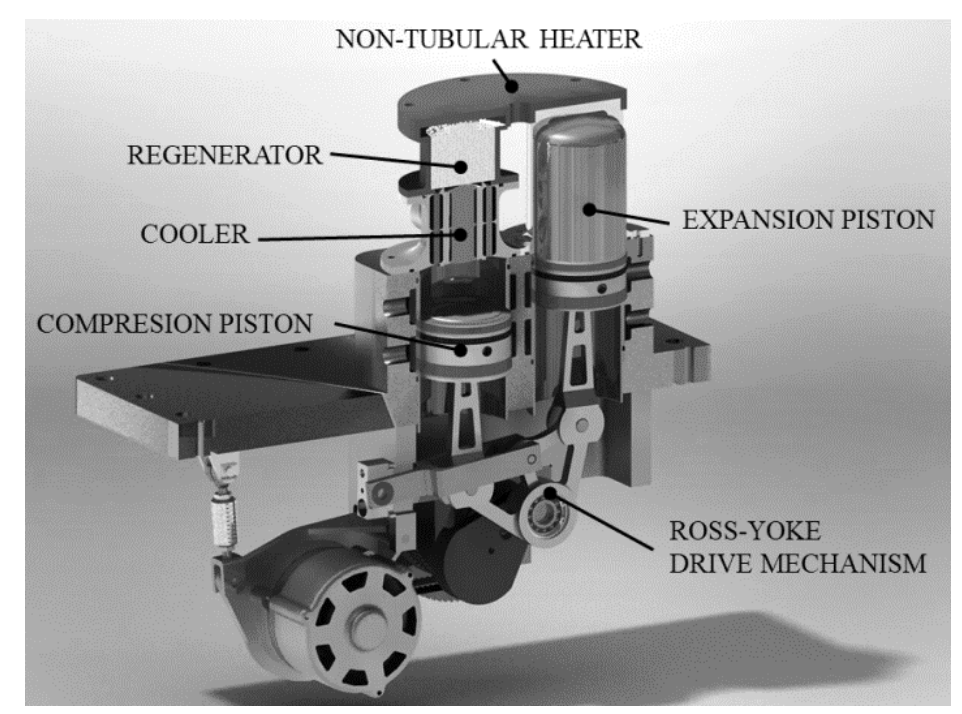

Figure 1. Experimental engine.

The non-tubular heater consists of a circular flat plate designed to receive and absorb the concentrated solar radiation. In the opposite face of the absorbing surface, almost a thousand cylindrical pins are arranged in a staggered manner to transfer the heat to the gas working fluid that circulates alternately inside the engine. The gas enters and exits the heater through two circular sections that are connected to the expansion cylinder and the regenerator casing, as shown in Figure 2 . 


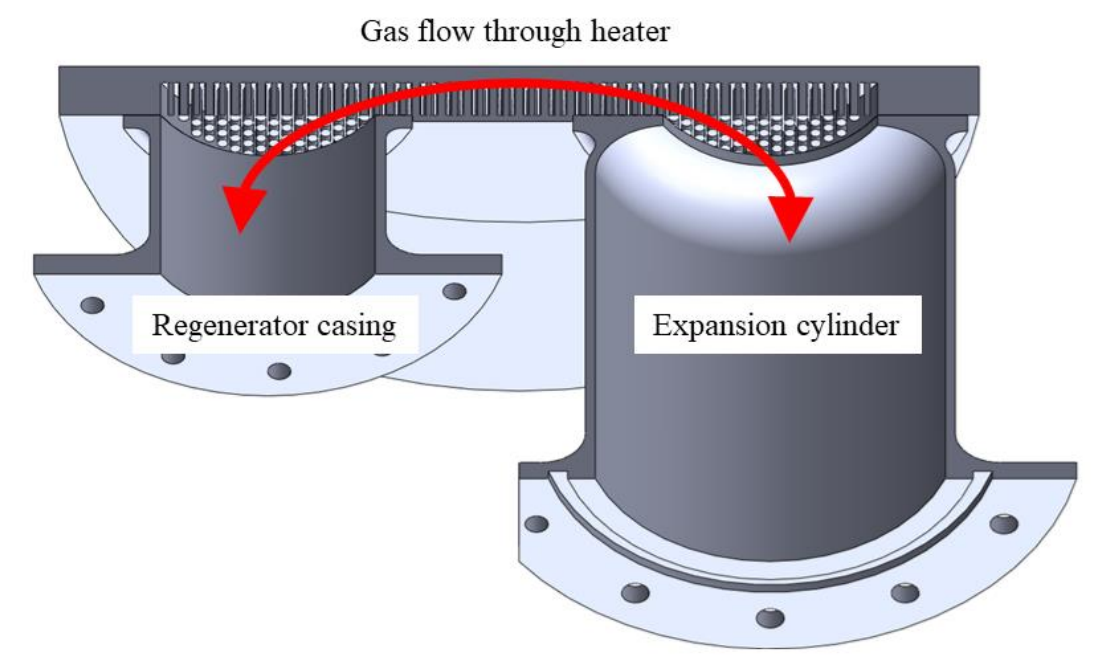

Figure 2. Conceptual sketch of the non-tubular heater.

The application of friction factor and Stanton or Nusselt number steady flow correlations for Stirling engine heat exchangers is open to discussion because the engine operation implies not-fully-developed, bidirectional flow with variable mass rate. However, the scarcity of data for complex geometries justifies experimentation under simplified conditions.

Experimental characterization for stationary unidirectional flow has been performed through 183 measurements obtained by a mass flow meter, a pressure transducer, a differential manometer and a set of thermocouples, which enabled the construction of graphs and correlations expressed by characteristic dimensionless variables [26].

The subsequent revision of these correlations made it possible to detect a generalized error in the Stanton number, whose correct values are 4 times larger than those previously calculated. Furthermore, in the notation section, the factor 4 must be suppressed in the definition of the characteristic hydraulic radius of the heater; however, this is merely a misprint that does not affect the correlations.

Before making the modifications derived from the aforementioned errors, it was considered appropriate to evaluate if the correlations should also be revised because the gas temperature measurements could be distorted by the heat radiation incident on the thermocouple junctions. This matter was not considered in the previous work, but it can become important if one considers that gas temperature measurements are used to validate a CFD model, as is shown later.

The temperature of the gas was measured using groups of four thermocouples, each arranged in the inlet and outlet sections of the heater. The wall temperature, $T_{w}$, was measured by a thermocouple inserted through a hole as close as possible to the bases of the pins. Another thermocouple was placed in contact between the electrical resistance used as a heat input and the outer flat surface of the heater, providing the setpoint signal for the power controller.

To analyse the thermal behaviour of a thermocouple junction, it can be modelled as a small sphere exposed to convective heat transfer to/from the gas flow, radiation heat transfer to/from the surroundings and conduction heat transfer across the thermocouple wires themselves [27]. If conduction heat transfer is neglected and it is assumed that the thermocouple junction reaches the stationary conditions, the following heat balance can be written:

$$
\varepsilon \sigma_{0}\left(T_{w}^{4}-T_{T C}^{4}\right)=h\left(T_{T C}-T_{g}\right)
$$

which allows the gas temperature $T_{g}$ to be derived from the thermocouple measurement $T_{T C}$ if the convective heat transfer coefficient $h$ can be determined. 
101

102

103

104

105

106

107

108

109

110

111

112

113

114

115

116

117

118

119

120

121

If it is accepted that the gas temperature at the heater inlet $T_{g i}$ can be identified with the outlet temperature of the air supply network, the equation (1) can be applied at this section to estimate the convective heat transfer coefficient, as follows:

$$
h=\frac{\varepsilon \sigma_{0}\left(T_{w}^{4}-T_{T C i}^{4}\right)}{\left(T_{T C i}-T_{g i}\right)}
$$

Assuming that the convective heat transfer between thermocouples and gas can be expressed at both ends of the heater by means of similar coefficients, Eq. (1) and (2) can be combined to obtain the gas temperature at the outlet of the heater, $T_{g_{0}}$ :

$$
T_{g o}=T_{T C o}-\frac{\left(T_{w}^{4}-T_{T C o}^{4}\right)}{\left(T_{w}^{4}-T_{T C i}^{4}\right)}\left(T_{T C i}-T_{g i}\right)
$$

This type of correction is justified based on Table 1, which lists the comparisons between the measurements of thermocouples at the inlet and outlet sections and the corresponding gas temperatures corrected by Eq. (3). The 12 data series shown correspond to the experimental tests that will be used in later sections to validate the CFD model of the heater. As predicted, the thermocouple data overestimate the gas temperature values and the percentage differences are higher at the inlet section.

Table 1. Comparison between thermocouple measurements and corrected gas temperatures.

\begin{tabular}{cccccccc}
\hline Test No. & $\begin{array}{c}\boldsymbol{T}_{\boldsymbol{w}, \boldsymbol{e x p}} \\
(\mathbf{K})\end{array}$ & $\begin{array}{c}\boldsymbol{T}_{\boldsymbol{g} \boldsymbol{i}} \\
(\mathbf{K})\end{array}$ & $\begin{array}{c}\boldsymbol{T}_{\boldsymbol{T C} \boldsymbol{i}} \\
\mathbf{( K )}\end{array}$ & $\begin{array}{c}\text { Dif. } \\
\mathbf{\%}\end{array}$ & $\begin{array}{c}\boldsymbol{T}_{\boldsymbol{g o}} \\
(\mathbf{K})\end{array}$ & $\begin{array}{c}\boldsymbol{T}_{\boldsymbol{T C o}} \\
(\mathbf{K})\end{array}$ & $\begin{array}{c}\text { Dif. } \\
\boldsymbol{\%}\end{array}$ \\
\hline 1 & 364 & 293 & 313 & 6.8 & 312 & 327 & 4.6 \\
2 & 358 & 293 & 314 & 7.2 & 316 & 330 & 4.2 \\
3 & 348 & 293 & 311 & 6.1 & 336 & 340 & 1.2 \\
4 & 339 & 293 & 304 & 3.8 & 318 & 323 & 1.5 \\
5 & 450 & 293 & 341 & 16.4 & 385 & 408 & 5.6 \\
6 & 446 & 293 & 342 & 16.7 & 383 & 406 & 5.7 \\
7 & 384 & 293 & 316 & 7.8 & 372 & 375 & 0.8 \\
8 & 549 & 293 & 377 & 28.7 & 409 & 463 & 11.7 \\
9 & 474 & 293 & 335 & 14.3 & 433 & 445 & 2.7 \\
10 & 662 & 293 & 410 & 39.9 & 514 & 574 & 10.5 \\
11 & 536 & 293 & 366 & 24.9 & 498 & 513 & 2.9 \\
12 & 533 & 293 & 362 & 23.5 & 476 & 497 & 4.2 \\
\hline
\end{tabular}

Once the gas temperature measurements have been corrected using Eq. (3), friction coefficient and Stanton number correlations have been re-calculated, obtaining the results of Eq. (4) and (5) that provide characteristic values of the entire heater as a function of the variable flow conditions, gas type and temperatures. The correlations adjust to the experimental data with R-squared values of 0.9868 and 0.9948 . The RMSE obtained were $9.67 \%$ for the friction coefficient correlation and $8.78 \%$ for the Stanton number correlation.

$$
\begin{gathered}
C_{f}=0.8437 N_{r e}^{-0.14}\left(\frac{\overline{T_{g}}}{T_{w}}\right)^{-1.24} \\
N_{s t}=0.007724 N_{r e}^{0.106} N_{p r}^{-4.3}\left(\frac{\Delta T_{g}}{T_{w}}\right)^{0.74}\left(\frac{\overline{T_{g}}}{T_{w}}\right)^{3.063}
\end{gathered}
$$


Figures 3 and 4 provide graphic comparisons between the experimental values and the correlation results. As can be observed, most experimental data fit within the limits of $\pm 10 \%$ indicated by dashed lines.

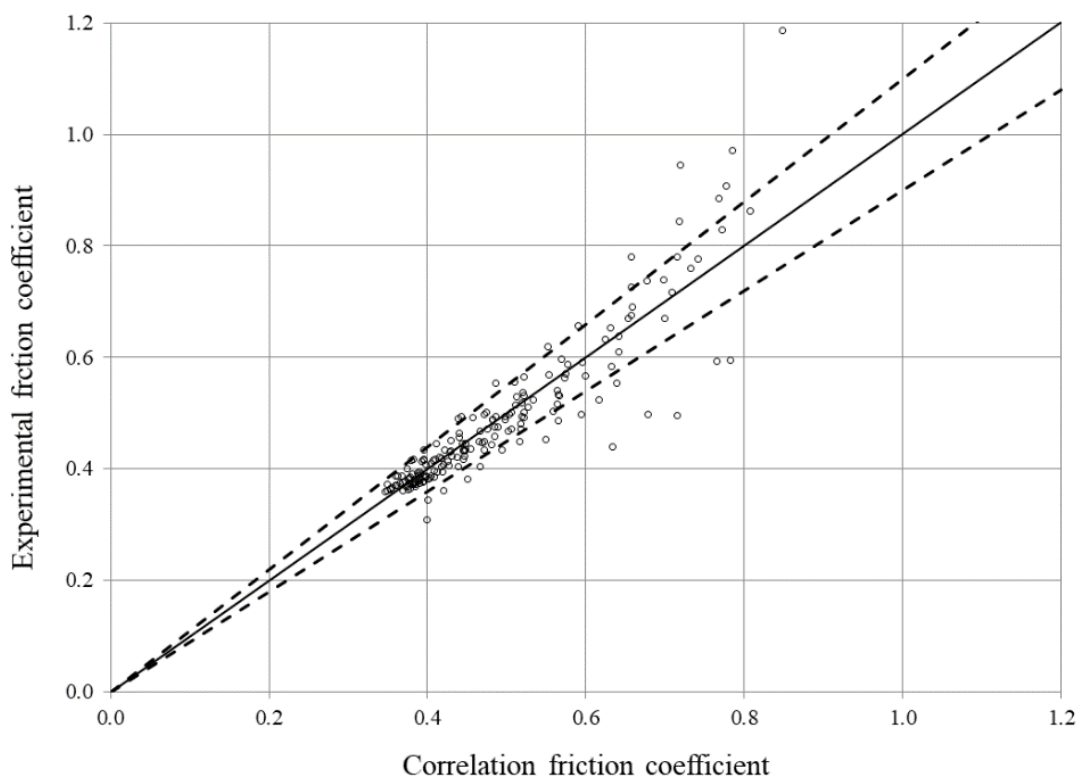

Figure 3. Comparison between the experimental friction coefficient and the correlation estimations based on Eq. (4).

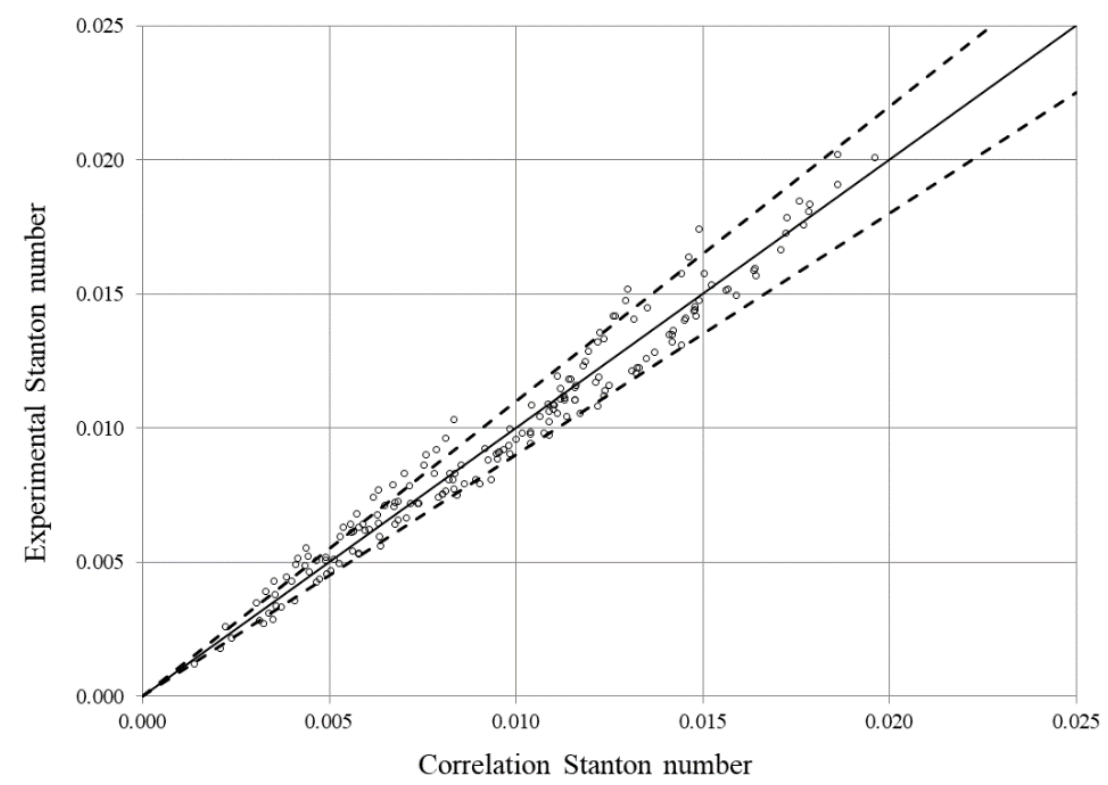

Figure 4. Comparison between the experimental Stanton number and the correlation estimations based on Eq. (5).

\section{CFD model of the heater performance}

Owing to instrumental limitations, the experimental characterization of the heater could not be extended for Reynolds numbers higher than 1100. A CFD model has been created with the main objective of extending the range of application of the correlations so that they can provide a basis for the analysis of the engine operation. It is expected that the model can serve additionally as a starting point for subsequent works of geometric optimization of the heater.

The numerical simulations have been performed using the CFD code FLUENT 6.3.26, which allows simultaneously dealing with the problems of heat transfer and fluid dynamics by solving the Navier-Stokes equations through the finite volume method. Given the satisfactory results obtained 
for similar cases with turbulent flows and heat transfer [28], the k- $\varepsilon$-RNG model was selected to consider the turbulence effects in the fluid flow, including buoyancy effects.

\subsection{Discretization, boundary conditions and other assumptions}

The discretized 3D geometry has been generated by using the software GAMBIT. Symmetry allows the calculation of only half of the heater. The domain was discretized with an unstructured mesh formed by a prism and tetrahedral cells. The mesh was refined at regions with potentially higher field gradients, mostly near the pins (Figure 5). The solid materials that make up the walls of the heater were also meshed to include the effects of heat conduction through them. The computations were made with a mesh of 1,300,000 cells approximately, which is expected to achieve enough detail in the pins.

As real gas effects are not expected for the air working fluid at the engine operating conditions [23], the ideal gas model has been assumed in the simulations. As regards the solid materials, the experimental heater is made of steel AISI 321, with density of $7,900 \mathrm{~kg} / \mathrm{m}^{3}$ and thermal conductivity that varies linearly with the temperature from $15 \mathrm{~W} /(\mathrm{m} \cdot \mathrm{K})$ at $20^{\circ} \mathrm{C}$ to $21 \mathrm{~W} /(\mathrm{m} \cdot \mathrm{K})$ at $500^{\circ} \mathrm{C}$.

The thermal boundary conditions assumed on the external walls consider the heat transmitted by convection and radiation. It is assumed that the heat flow is uniform on the external surface in contact with the electrical resistance arranged for heat supply, with values that are modified according to each experiment. For the rest of the external surface, the uniform value of $16 \mathrm{~W} /\left(\mathrm{m}^{2} \cdot \mathrm{K}\right)$ was set for the convective heat transfer coefficient and the values of 0.9 and $20^{\circ} \mathrm{C}$ were assumed for the external emissivity and ambient temperature, respectively.

Regarding the air inlet and outlet, the air enters into the heater at the outlet temperature of the air supply network, which is $293 \mathrm{~K}$ for all experimental cases, and the temperature of the outgoing air is one of the results obtained in the numerical simulations. A mass flow inlet condition was used for the incoming air flow and was changed for each experiment. The inlet air pressure was also changed in each experiment and defined as a constant value at the exit. The pressure loss is another result obtained in the simulations.

Finally, to provide for accurate calculations, a second-order discretization has been chosen, while for the convergence it has been established that the value of the normalised residuals should fall below $10^{-5}$.

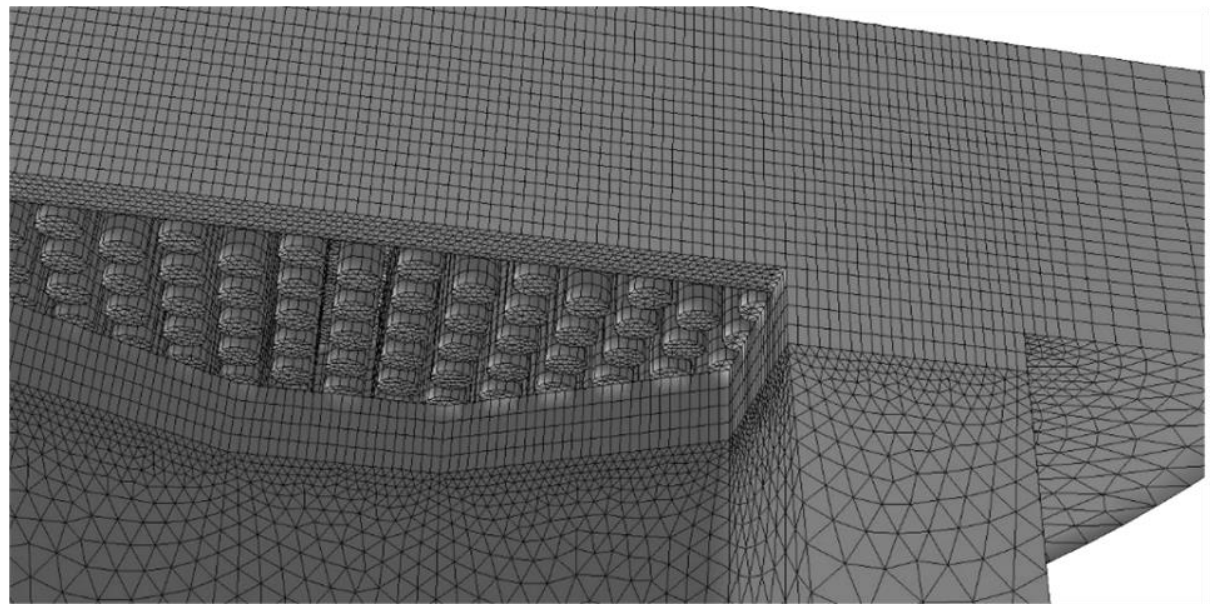

Figure 5. Detail of mesh refinement.

\subsection{Model results and validation}

The CFD model has been run for 12 different test conditions that have been selected among the 183 experimental series. The numerical results obtained are listed in Table 2 to facilitate the comparisons with the experimental data. It is noted that the mass flow values shown in the table correspond to half of the values circulating through the heater because only half of it is simulated. 
Table 2. Comparison between experimental data and numerical results.

\begin{tabular}{|c|c|c|c|c|c|c|c|c|c|c|}
\hline Test No. & $\begin{array}{c}\dot{m} \\
(\mathrm{~kg} / \mathrm{s})\end{array}$ & $\begin{array}{c}T_{g o, e x p} \\
(\mathrm{~K})\end{array}$ & $\begin{array}{c}T_{g o, s i m} \\
(\mathrm{~K})\end{array}$ & $\begin{array}{l}\text { Dif. } \\
(\%) \\
\end{array}$ & $\begin{array}{c}T_{w, \exp } \\
(\mathrm{K}) \\
\end{array}$ & $\begin{array}{c}T_{w, s i m}^{*} \\
(\mathrm{~K})\end{array}$ & $\begin{array}{c}\boldsymbol{T}_{w, \operatorname{sim}}^{* *} \\
(\mathrm{~K})\end{array}$ & $\begin{array}{c}\Delta p_{\text {exp }} \\
(\mathrm{Pa}) \\
\end{array}$ & $\begin{array}{c}\Delta \boldsymbol{p}_{\text {sim }} \\
(\mathrm{Pa})\end{array}$ & $\begin{array}{l}\text { Dif. } \\
(\%) \\
\end{array}$ \\
\hline 1 & 0.00027 & 312 & 312 & 0.0 & 364 & 314 & 310 & 21 & 25 & 19.0 \\
\hline 2 & 0.00027 & 316 & 316 & -1.3 & 358 & 318 & 313 & 38 & 38 & 0.0 \\
\hline 3 & 0.00055 & 336 & 336 & 0.0 & 348 & 342 & 328 & 107 & 96 & -10.3 \\
\hline 4 & 0.00126 & 318 & 318 & 0.0 & 339 & 329 & 312 & 449 & 331 & -26.3 \\
\hline 5 & 0.00045 & 385 & 385 & 0.0 & 450 & 396 & 402 & 40 & 36 & -10.0 \\
\hline 6 & 0.00040 & 383 & 383 & 0.0 & 446 & 393 & 369 & 57 & 51 & -10.5 \\
\hline 7 & 0.00198 & 372 & 372 & 0.0 & 384 & 427 & 354 & 812 & 618 & -23.9 \\
\hline 8 & 0.00033 & 409 & 409 & 0.2 & 549 & 420 & 394 & 95 & 62 & -34.7 \\
\hline 9 & 0.00152 & 433 & 433 & 0.0 & 474 & 502 & 401 & 611 & 430 & -29.6 \\
\hline 10 & 0.00030 & 514 & 514 & 0.6 & 662 & 535 & 491 & 17 & 18 & 5.9 \\
\hline 11 & 0.00164 & 498 & 498 & 0.0 & 536 & 601 & 453 & 694 & 483 & -30.4 \\
\hline 12 & 0.00123 & 476 & 476 & 0.0 & 533 & 544 & 434 & 854 & 580 & -32.1 \\
\hline
\end{tabular}

It is observed that the temperatures of the gas at the exit of the heater are practically the same as those measured experimentally for all the simulated cases, which is interpreted as a validation of the numerical model.

Experimental measurements of heater wall temperatures, $T_{w, \exp }$ are also shown in the table. It should be noted that these measurements were made in a single point, using a $\mathrm{K}$ type thermocouple installed perpendicular to the flat surface of the heater and in contact with the base of the pins. (Figure 6). This solution was adopted to have an approximate value for the temperature level of the heat source, being aware of the practical difficulties to achieve a measure whose representativeness was unquestionable.

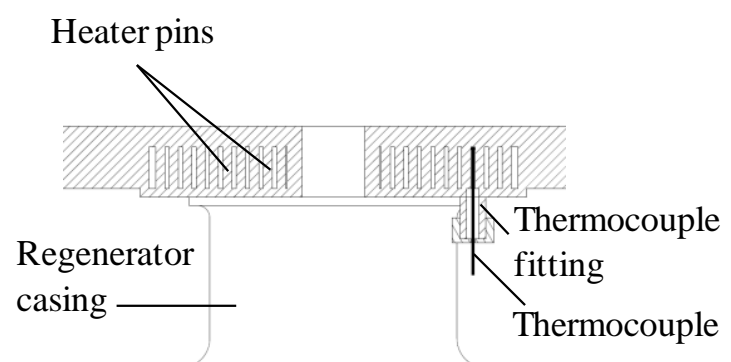

Figure 6. Detail of the thermocouple arrangement.

The wall temperature of the heater is a variable of considerable conceptual importance for the analysis and design of a Stirling engine because it determines the maximum values of power and indicated efficiency that the engine could reach if the heat sources had infinite heat capacity and losses due to irreversibilities, heat conduction, leakage, or any other cause did not exist.

Such ideal conditions would imply that the heat sources had constant temperature and that the cycle was formed by quasi-static processes, i.e., by successive states of quasi-equilibrium between the working gas and the walls of the heat sources. Therefore, the coefficient of convective heat transfer in each exchanger would have to be infinite. In addition, if the walls of the heater and the cooler had uniform temperatures, the thermodynamic processes in both heat exchangers would have to be isothermal, while in the regenerator the working gas would perform alternating heating and cooling processes, adapting its temperature to the local values determined by the thermal gradient of the regenerator.

For the heater analysed in this article it is not possible to achieve a uniform wall temperature because the geometry adopted causes the temperature along the length of the pins to be variable 
even under conditions of stationary heat conduction. It can be said that the geometry prevents reaching the theoretical thermodynamic roofs that would correspond to the highest values of wall temperature, i.e., those reached at the base of the rods, producing an effect similar to that caused by thermal irreversibility.

In this sense, the CFD model is a good complement to experimentation because it enables the estimation of variables whose measurement is practically unviable. The following figures make it possible to demonstrate for one of the simulated cases the complexity of the temperature distributions of the heater material and gas and to interpret the information contained in Table 2.

In Figure 7, the values of wall and gas temperatures correspond to points located in a horizontal plane drawn halfway up the height of the pins, including the circular steel plate around the heater. It is observed that there is a marked thermal gradient from the steel to the gas, showing the heat transfer direction. Most of the heat transfer occurs in the main chamber between the pins, and the maximum gas temperature is reached at the main chamber exit section. As expected, it is observed that the wall temperatures are lower in the vicinity of the gas, particularly at the inlet section. The average of the wall temperatures, calculated for the total points of the horizontal plane passing through the outer circular surface, is designated in Table 2 as $T^{*}{ }_{w, s i m}$. It would seem coherent that the average value corresponding to the test of the figure, $544 \mathrm{~K}$, is somewhat higher than the measurement of the thermocouple, $533 \mathrm{~K}$, but in reality, the comparison between both values has no meaning, and in fact the differences have the opposite sign for other tests.

Continuing with arguments initiated in previous paragraphs, it should be noted that the wall temperature at the points of contact with the gas is not only the most significant variable from the thermodynamic point of view but also from the perspective of convective heat transfer. The average of said temperature could be calculated using the CFD model and is designated in Table 2 as $T^{* *}{ }_{w, s i m}$.

Figures 8 and 9 allow the visualization of the thermal gradient of temperatures in the vertical direction, that is to say, parallel to the longitudinal axis of each cylinder. The colour scale allows estimating a wall temperature of the order of $500 \mathrm{~K}$ in points close to the position of the thermocouple, which does not differ much from the experimental value. The previous values seem coherent with the value $T^{* *}{ }_{w \text {,sim }}=434 \mathrm{~K}$ corresponding to this test, as the temperature of each pin decreases from the base. Although the comparison between a point measure and an average value is generally spurious, it is interesting to note that $T_{w, \text { exp }}>T^{* *}{ }_{w, s i m}$ for all tests (Figure 10), as it seems to indicate that the location of the thermocouple has been successful.

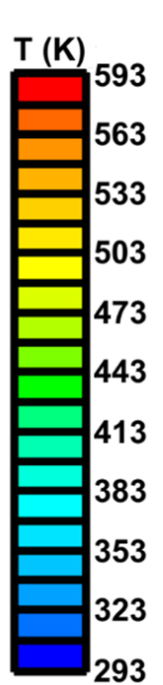

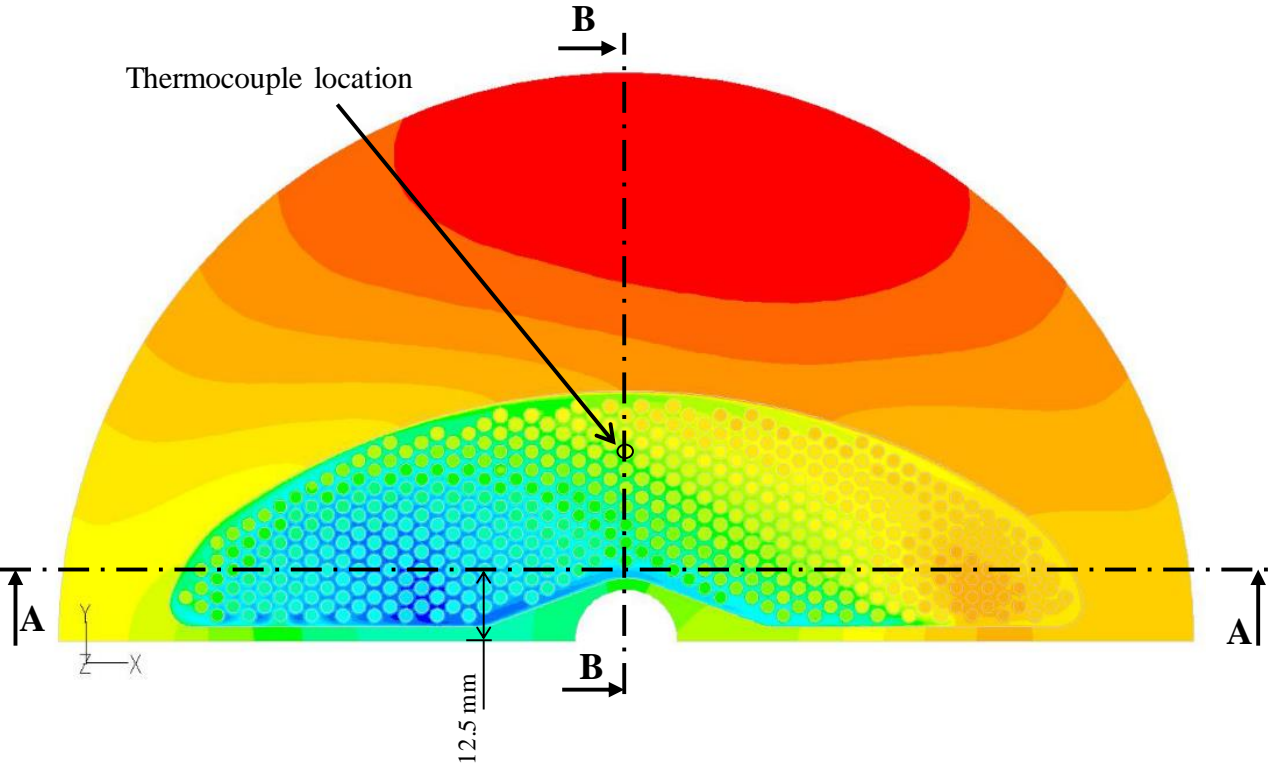

Figure 7. Wall and gas temperatures for the No.12 test (horizontal cross-section at half height of the pins). 


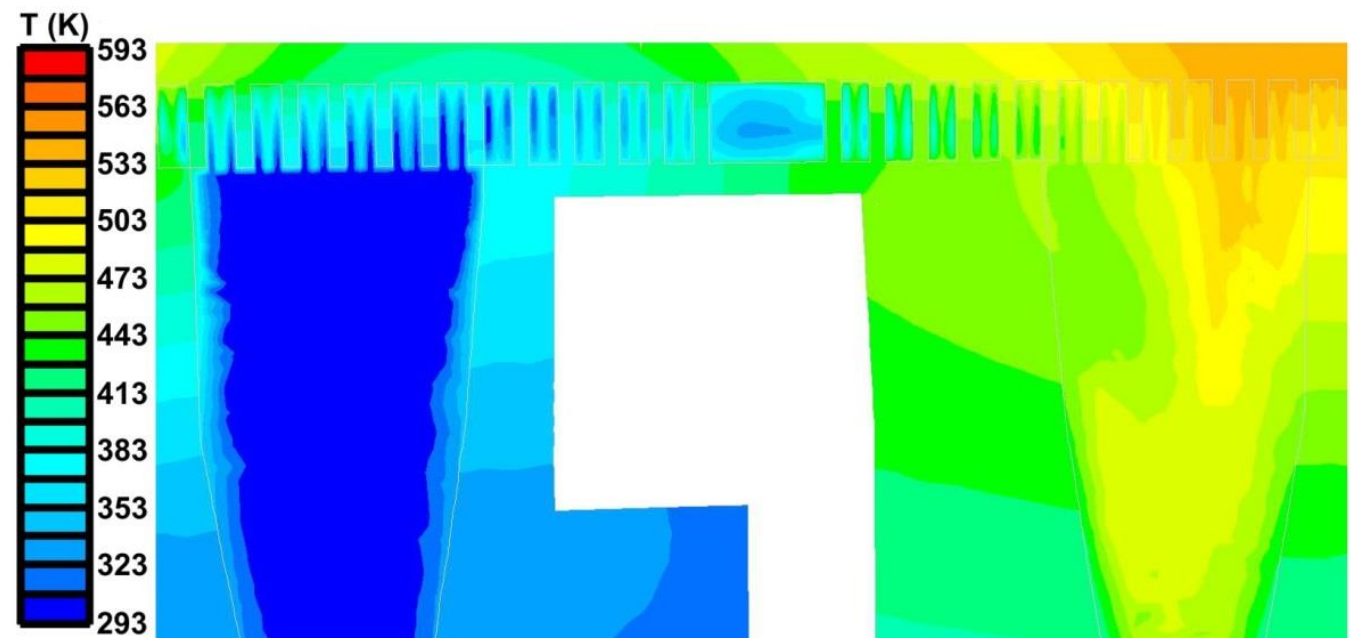

$238 \quad$ Figure 8. Wall and gas temperatures for the No.12 test (vertical A-A section).

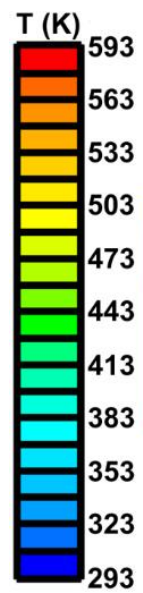

240 Figure 9. Wall and gas temperatures for the No.12 test (vertical B-B section).

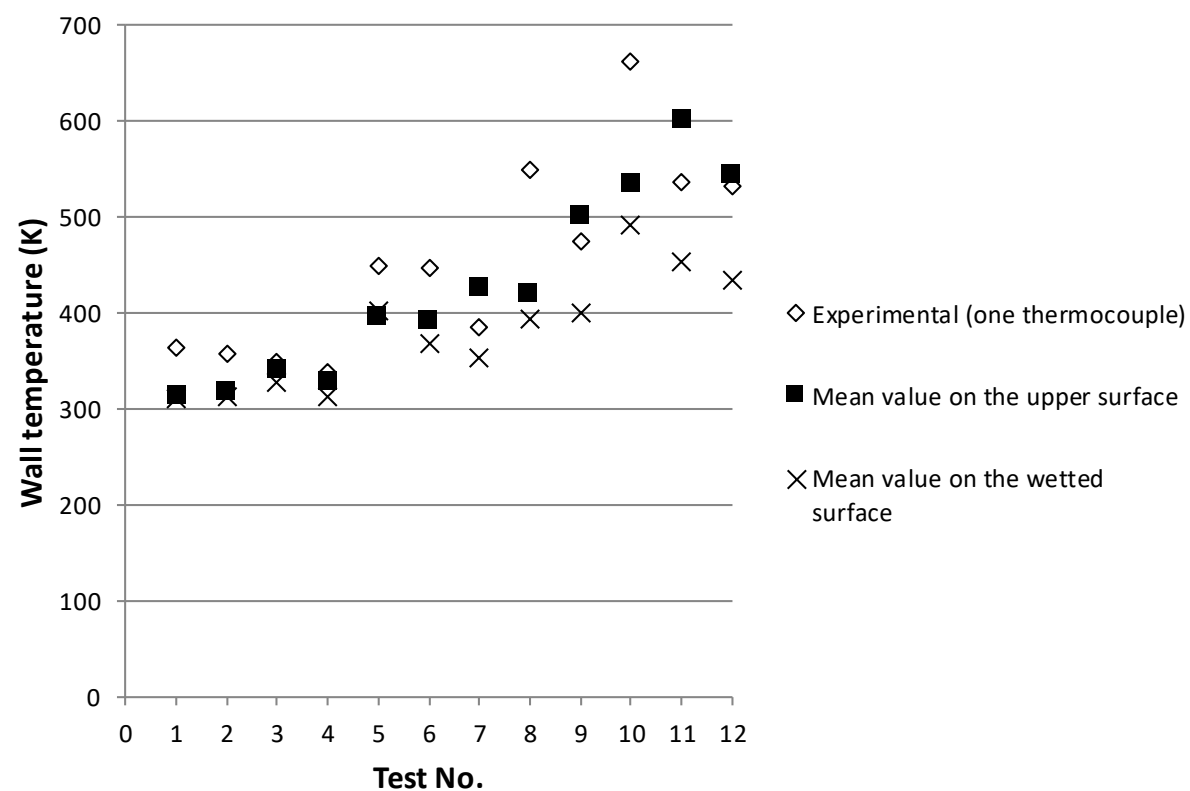

Figure 10. Comparison between wall temperature values. 
Regarding the pressure losses along the heater, Figure 11 provides an image of the air pressure values that have been obtained by the CFD model for the No.12 test in a cross-section of the heater. It can be observed that the pressure distribution is quite uniform in the transversal direction and that there is an approximately constant gradient along the fluid flow trajectory. This difference is mainly due to the pressure losses because the velocity changes are small.

Table 2 lists the differences between the experimental values and the results of the CFD model, which have different values that may be outside the acceptable margins of error in half of the cases. To improve this issue in future work, it seems that a finer mesh will have to be made in the rods and their vicinity.

In summary, it is considered that the CFD model acceptably reproduces the behaviour of the heater for the analysed tests and can be used for simulations under different conditions. With respect to possible comparisons between the results of equations (4) and (5) and simulations using the CFD model, apparent inconsistencies may occur, as a particular simulation may be relatively far from the trend lines of the correlations, which have been derived from dozens of tests. In any case, it is recommended to previously check the coherence between wall temperatures using similar reasoning to those explained in previous paragraphs, especially while verifying that $T_{w, \exp }>$ $T^{* *}{ }_{w, s i m}$.

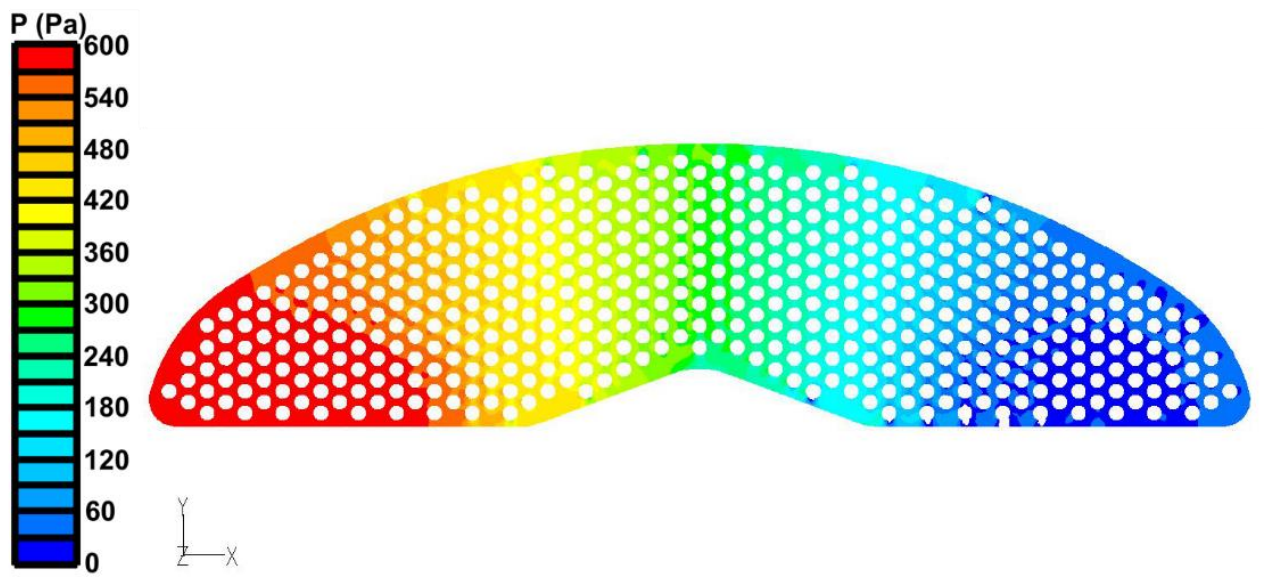

Figure 11. Pressure distribution for the No.12 test.

\section{Analysis of engine performance}

\subsection{Description of the analysis procedure}

So far, it has not been sufficiently emphasized that classical criteria, such as the Beale number, cannot be used to estimate the power of a Stirling engine unless the imposition of a particular value of engine speed can be acceptable [15, 17].

To solve this limitation, the following semi-empirical equation has been proposed to explicitly describe the influence of the engine speed on the indicated power of kinematic Stirling engines [15]:

$$
\zeta_{\text {ind }}=\zeta_{0}-\Phi N_{M A}-\Psi N_{M A}^{2}
$$

In this equation, $\zeta_{0}$ is the dimensionless quasi-static work per cycle, i.e., a thermodynamic concept that represents the theoretical limit of the gas circuit performance, which depends on the temperature ratio $\tau$ and the geometric engine parameters but not on the working fluid, mean pressure or engine speed, while the coefficients $\Phi$ and $\Psi$ are macroscopic representations of the indicated power losses associated with irreversibilities inherent to working gas friction and heat transfer. $N_{M A}$ is an operating characteristic variable that can be interpreted as a dimensional engine speed.

Experimental data of Stirling engines of varying size and characteristics have been analysed and the following empirical correlations have recently been proposed for the dimensionless values 
of the maximum indicated power and its corresponding velocity, including ranges of operation in which real gas effects could occur [23]:

$$
\begin{gathered}
\zeta_{\text {ind,max }}=2.249 \zeta_{0}^{1.054}\left(\frac{R_{h R}}{L_{R}}\right)^{0.190} \\
N_{M A, \text { max }}=0.001913(1-\tau)^{0.355}\left(\frac{R_{h R}}{L_{R}}\right)^{0.223} \gamma^{-0.220}\left(\sum \mu_{d x}\right)^{0.217} N_{p}^{0.146}
\end{gathered}
$$

Equation (6) leads to the following relationships which allow the coefficients $\Phi$ and $\Psi$ to be calculated for each level of temperature and mean pressure, and consequently to obtain characteristic maps of indicated power:

$$
\begin{gathered}
\Phi=\frac{2 \zeta_{0}-3 \zeta_{\text {ind,max }}}{N_{M A, \max }} \\
\Psi=\frac{2 \zeta_{\text {ind,max }}-\zeta_{0}}{N_{M A, \max }^{2}}
\end{gathered}
$$

The brake power performance can be analysed through the following empirical correlations recently proposed for the dimensionless values of the maximum brake power and its corresponding velocity [23]:

$$
\begin{gathered}
\zeta_{B, \max }=2.301 \zeta_{0}^{1.087}\left(\frac{R_{h R}}{L_{R}}\right)^{0.119} N_{p}^{-0.039} \\
N_{M A, \max }^{*}=0.00202(1-\tau)^{0.485}\left(\frac{R_{h R}}{L_{R}}\right)^{0.414} \gamma^{-0.493}\left(\sum \mu_{d x}\right)^{0.029} N_{p}^{0.220}
\end{gathered}
$$

\subsection{Nominal operating characteristics}

The non-tubular heater is part of an experimental alpha type Stirling engine with a Ross-yoke drive mechanism and air as the working fluid, whose main characteristics are summarized in Table 3.

Table 3. Main characteristics of the experimental Stirling engine.

\begin{tabular}{ccccccccc}
\hline $\begin{array}{c}\boldsymbol{V}_{\boldsymbol{s w}} \\
(\mathrm{cc})\end{array}$ & $\begin{array}{c}\sum \boldsymbol{V}_{\boldsymbol{d x}} \\
(\mathrm{cc})\end{array}$ & $\begin{array}{c}\boldsymbol{A}_{w x e} \\
\left(\mathrm{~cm}^{2}\right)\end{array}$ & $\begin{array}{c}\boldsymbol{L}_{\boldsymbol{R}} \\
(\mathrm{mm})\end{array}$ & $\begin{array}{c}\boldsymbol{R}_{\boldsymbol{h R}} \\
(\mathbf{m m})\end{array}$ & $\begin{array}{c}\boldsymbol{\gamma} \\
(--)\end{array}$ & $\begin{array}{c}\boldsymbol{p}_{\boldsymbol{m}} \\
(\mathrm{bar})\end{array}$ & $\begin{array}{c}\boldsymbol{T}_{\boldsymbol{w}} \\
\left({ }^{\circ} \mathrm{C}\right)\end{array}$ & $\begin{array}{c}\boldsymbol{T}_{\boldsymbol{w} C} \\
\left({ }^{\circ} \mathrm{C}\right)\end{array}$ \\
\hline 341.82 & 204.06 & 817.00 & 45 & 0.090 & 1.4 & 6.9 & 600 & 60 \\
\hline
\end{tabular}

For the nominal mean pressure and temperatures listed in the table, the value $\zeta_{0}=0.302$ has been obtained from the quasi-static simulation of the thermodynamic cycle. This result has been calculated via a numerical simulation of the drive mechanism, although the Schmidt model can provide an approximate value. For the same conditions, equations (11) and (12) give the values $\zeta_{B, \max }=0.161$ and $N_{M A, \max }^{*}=0.00335$, respectively. Therefore, the maximum brake power of $P_{B, \max }=562 \mathrm{~W}$ can be predicted for the operation at the engine speed of $888 \mathrm{rpm}$, which exceeds the objective set at the preliminary design stage [26].

With respect to the indicated power, the values $\zeta_{\text {ind,max }}=0.196$ and $N_{M A, \max }=0.00340$ are deduced, respectively, from equations (7) and (8), so that the engine would develop a maximum indicated power of $694 \mathrm{~W}$ at $902 \mathrm{rpm}$.

To calculate the indicated power at the engine speed of maximum brake power, it is necessary to previously use equations (9) and (10) to obtain the coefficients of indicated power losses, which turn out to be equal to $\Phi=5.16$ and $\Psi=7700$ for the conditions of temperatures and mean 
pressure assumed. Therefore, under nominal conditions, the experimental engine would develop an indicated power of $693 \mathrm{~W}$ at $888 \mathrm{rpm}$.

The CFD model can be used to estimate the engine efficiency at this rotational engine speed. To establish the simulation conditions, the variation of the mass flow in the heater along a cycle has been analysed. As shown in Figure 12, the intervals of alternating unidirectional flow are separated by small intervals of zero mass flow rate, corresponding to bidirectional flow. Based on the integration of the absolute value of mass flow for the rest of intervals with unidirectional flow, in one or the other direction, an average mass flow rate of $0.0198 \mathrm{~kg} / \mathrm{s}$ is obtained. This value has been assumed in a CFD simulation with the main objective of estimating the heat absorbed by the gas in the heater during a cycle, with the results listed in Table 4.

Table 4. CFD results for nominal operating conditions.

\begin{tabular}{|c|c|c|c|c|c|c|c|c|}
\hline Test No. & $\begin{array}{l}n_{s, \max }^{*} \\
(\mathrm{rpm})\end{array}$ & $\begin{array}{c}\dot{m} \\
(\mathrm{~kg} / \mathrm{s})\end{array}$ & $\begin{array}{c}T_{g i, s i m} \\
(\mathrm{~K})\end{array}$ & $\begin{array}{c}T_{g o, s i m} \\
(\mathrm{~K})\end{array}$ & $\begin{array}{c}T^{*}{ }_{w, \text { sim }} \\
(\mathrm{K})\end{array}$ & $\begin{array}{c}T^{* *}{ }_{w, s i m} \\
(\mathrm{~K}) \\
\end{array}$ & $\begin{array}{c}\dot{Q}_{E, \text { sim }} \\
(\mathrm{W})\end{array}$ & $\begin{array}{c}\Delta p_{\text {sim }} \\
(\mathrm{Pa})\end{array}$ \\
\hline 13 & 888 & 0.00990 & 723 & 832 & 1023 & 810 & 1182 & 8951 \\
\hline
\end{tabular}

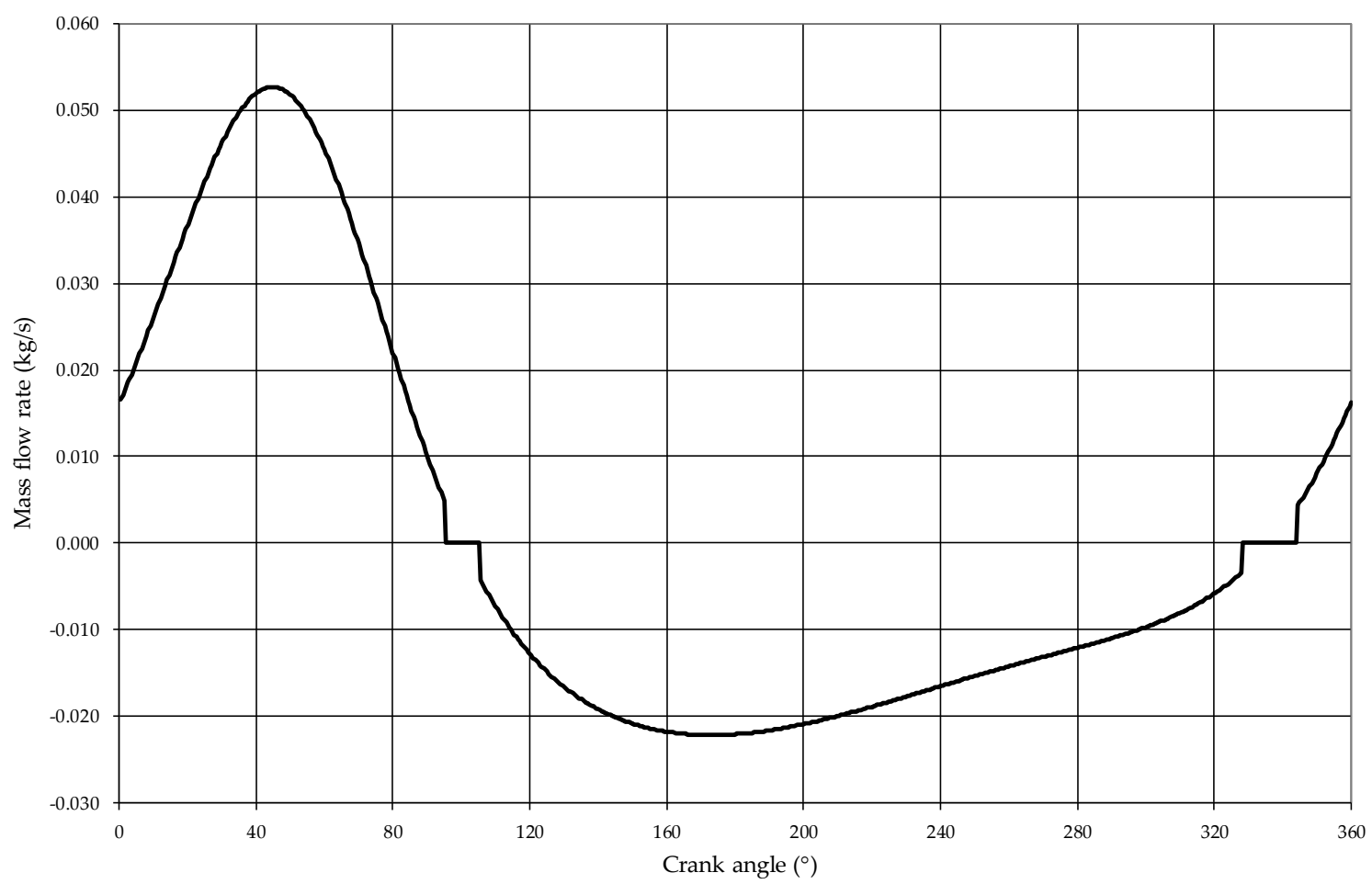

Figure 12. Mass flow rate in the heater for operating conditions.

Regarding the coherence of these results, it is observed that there is a 63-K difference between the average of the wall temperature in contact with the working fluid and the maximum wall temperature corresponding to the nominal conditions, i.e., $T_{w E}=873 \mathrm{~K}$. Although it is difficult to assess the degree of accuracy of this difference, the margin seems sufficient to take into account that $T^{* *}{ }_{w, s i m}$ is an average whose value must be less than the temperature at the base of the pins, which would be the temperature comparable with $T_{w E}$.

Thus, given that the CFD results of Table 4 refer to half the heater, it is deduced that the gas would absorb approximately $2364 \mathrm{~W}$ per cycle from the hot heat source, which allows a brake efficiency of the order of $24 \%$ to be estimated for the operating point considered.

There are no experimental data to corroborate the accuracy of the heat consumption predicted by the CFD model of the heater, but it seems interesting to note that the result is not very different 
from the value $\dot{Q}_{E} \approx 2200 \mathrm{~W}$ that would be obtained by applying the following correlation, obtained recently for the SOLO V160 engine [24] operating at not very different temperature conditions and engine speed but with different working gas and much higher pressures:

$$
\frac{\dot{Q}_{E}}{p_{m} V_{S w} n_{S}}=\frac{\zeta_{0}}{1-\tau}+8.871 N_{M A}^{0.101} N_{p}^{-0.230}
$$

Pending further research, the CFD model can be used to obtain a correlation similar to equation (13), which is necessary to estimate the engine efficiency for various conditions. For this purpose, the procedure used in test no.13 has been applied to additional tests for engine speeds from 600 to 1000 $\mathrm{rpm}$, maintaining the nominal conditions of temperatures. To consider the influence of $N_{p}$, the mean pressure values of 4, 5, 6 and 6.9 bar were also considered. The CFD results are listed in Table 5 and lead to the following correlation with RMSE $=4.58 \%$ and R-squared value of 0.9984 :

$$
\frac{\dot{Q}_{E}}{p_{m} V_{s w} n_{s}}=\frac{\zeta_{0}}{1-\tau}+6722.5 N_{M A}{ }^{-1.280} N_{p}^{-1.116}
$$

\begin{tabular}{|c|c|c|c|c|c|c|c|c|c|}
\hline Test No. & $\begin{array}{c}p_{m} \\
\text { (bar) }\end{array}$ & $\begin{array}{c}n_{s} \\
(\mathrm{rpm})\end{array}$ & $\begin{array}{c}\dot{m} \\
(\mathrm{~kg} / \mathrm{s})\end{array}$ & $\begin{array}{c}T_{g i, s i m} \\
(\mathrm{~K})\end{array}$ & $\begin{array}{c}T_{g o, \text { sim }} \\
\text { (K) }\end{array}$ & $\begin{array}{c}T^{*}{ }_{w, \text { sim }} \\
(\mathbf{K})\end{array}$ & $\begin{array}{c}T^{* *}{ }_{\boldsymbol{w}, \operatorname{sim}} \\
(\mathrm{K})\end{array}$ & $\begin{array}{c}\dot{Q}_{E, \text { sim }} \\
\text { (W) }\end{array}$ & $\begin{array}{c}\Delta p_{\text {sim }} \\
(\mathrm{Pa})\end{array}$ \\
\hline 14 & 6.9 & 600 & 0.0069 & 723 & 849 & 1023 & 822 & 1910 & 4539 \\
\hline 15 & 6.9 & 700 & 0.0081 & 723 & 843 & 1023 & 816 & 2121 & 6133 \\
\hline 16 & 6.9 & 800 & 0.0092 & 723 & 837 & 1023 & 804 & 2290 & 7882 \\
\hline 17 & 6.9 & 1000 & 0.0115 & 723 & 826 & 1023 & 811 & 2603 & 12100 \\
\hline 18 & 6.0 & 862 & 0.0086 & 723 & 840 & 1023 & 807 & 2196 & 8009 \\
\hline 19 & 5.0 & 828 & 0.0069 & 723 & 850 & 1023 & 815 & 1914 & 6270 \\
\hline 20 & 4.0 & 788 & 0.0053 & 723 & 862 & 1023 & 825 & 1619 & 4823 \\
\hline
\end{tabular}

Table 5. CFD results for different operating conditions.

From equations (6) and (14), the characteristic curves of indicated power and efficiency have been obtained for various values of mean pressure and nominal temperatures of the heat sources. Figure 13 shows the results for $T_{w E}=600^{\circ} \mathrm{C}$ and $T_{w C}=60^{\circ} \mathrm{C}$ with air as the working fluid using two types of diagrams.

In the $p_{m e}-n_{s}$ diagram, used by Philips decades ago [29], the lines of constant indicated power are exactly equilateral hyperbolas, because the mean effective pressure is defined as the power divided by the swept volume and the engine speed, while the dashed lines of constant efficiency have the typical appearance of a hill diagram. It is interesting to note that the values of $p_{m e}$ and dimensionless power are proportional, i.e.:

$$
p_{m e}=\zeta_{\text {ind }} p_{m}
$$

so that a single point of the diagram is sufficient to represent the power and efficiency values corresponding to each operation condition, as symbolized in Figure 13(a).

The second type of diagram is probably more used because the points of maximum power and efficiency are easy to identify. Figure 13(b) shows that the points of maximum indicated power correspond to velocities that increase slightly with the mean pressure, as corresponds to the positive exponent of $N_{p}$ in equation (8). In contrast, the maximum efficiency values correspond to velocities that decrease slightly with the mean pressure, as a consequence of the influence of $N_{M A}$ and $N_{p}$ in equation (14).

In summary, equations (6) to (12), complemented by equation (14) derived from the CFD model, allow estimating that, under nominal conditions, the experimental engine would develop an indicated power of $693 \mathrm{~W}$ at $888 \mathrm{rpm}$, with an indicated efficiency of $29.3 \%$ and a mechanical efficiency of $81.0 \%$. 


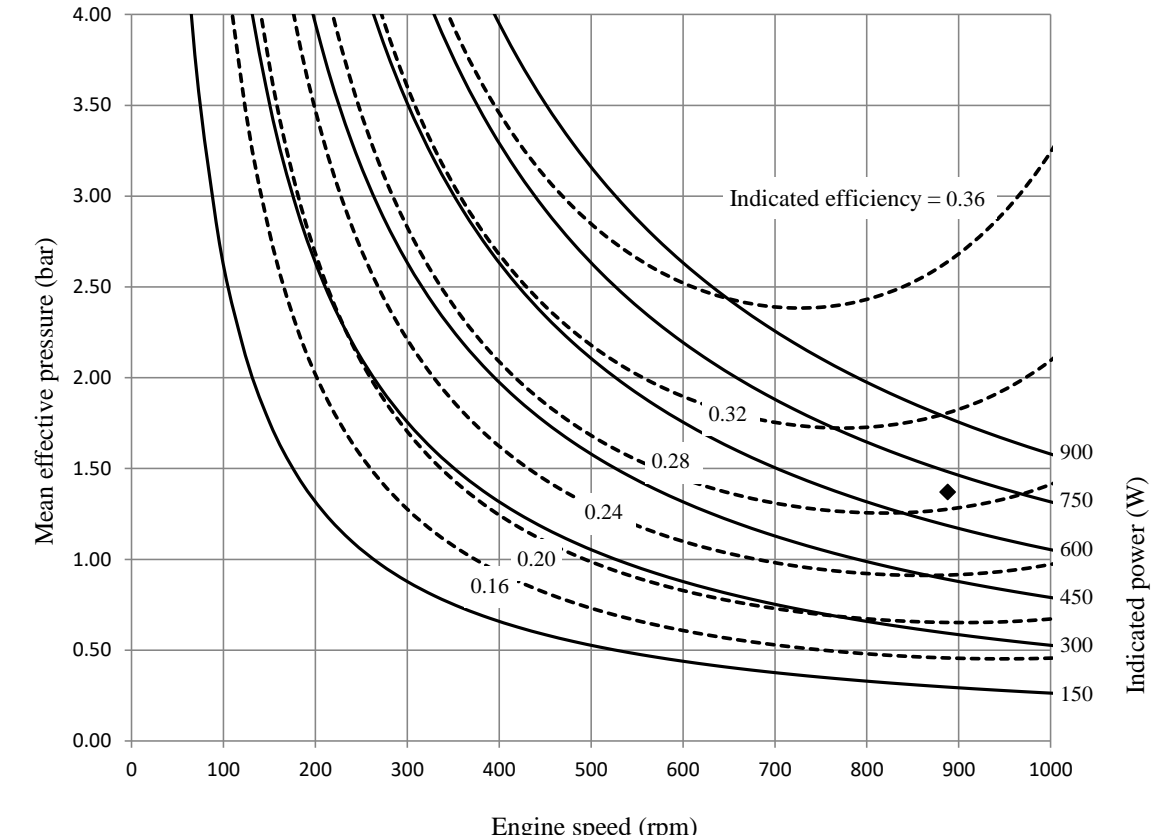

361

362

363

364

\section{(a)}

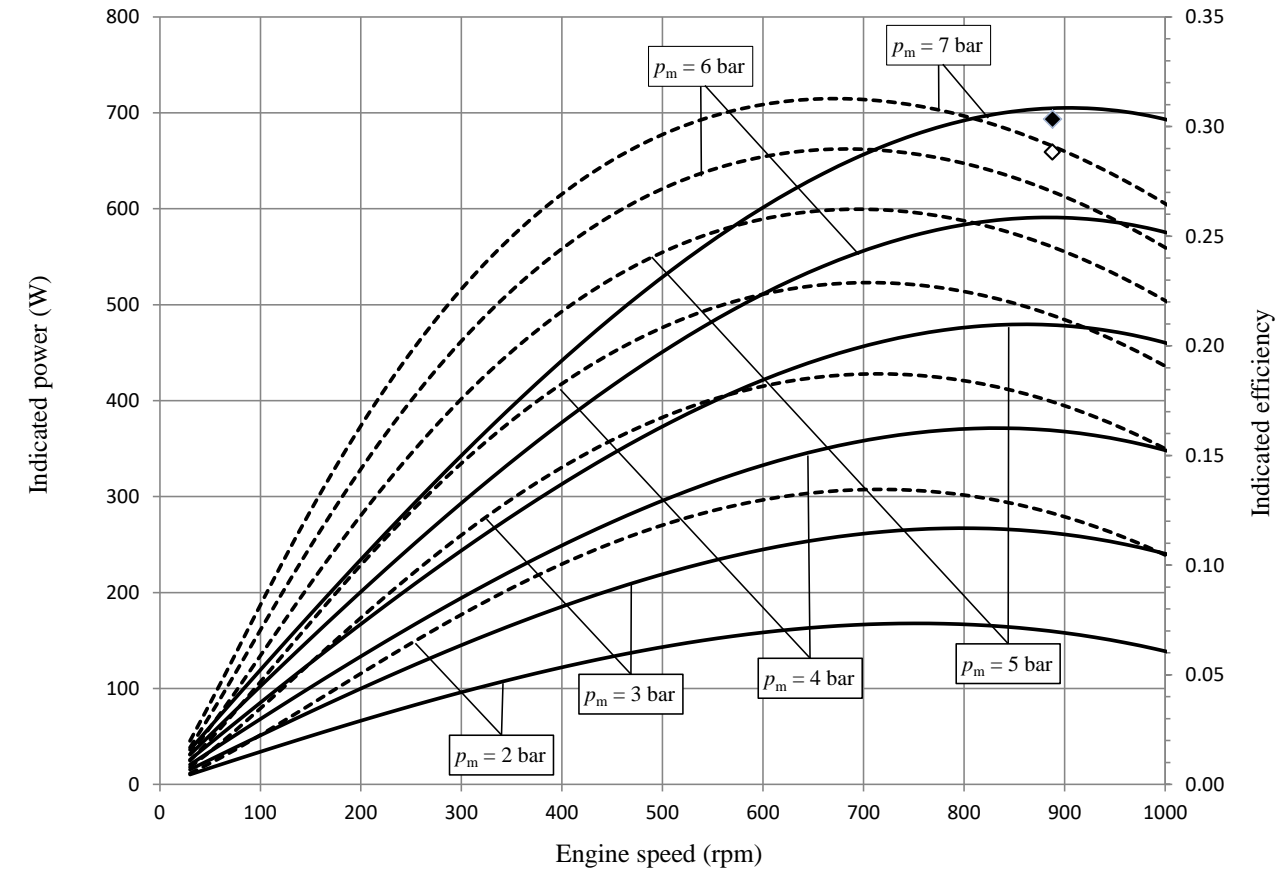

----- Indicated efficiency

$\diamond \quad$ Nominal indicated efficiency

(b)

Figure 13. Characteristic curves for $T_{w E}=600^{\circ} \mathrm{C}$ and $T_{w C}=60^{\circ} \mathrm{C}$ with air as the working fluid: (a) Indicated power and efficiency in the mean effective pressure $v s$ engine speed diagram; (b) Indicated power and efficiency $v$ s engine speed as a function of the mean pressure. 


\section{Conclusions}

The correlations previously obtained in the non-tubular heater for the friction factor and the Stanton number have been revised, including a correction of gas temperatures based on radiation effects in the measurements of the thermocouples. The revised correlations adjust to the 183 experimental data with R-squared values practically equal to 0.99 and RMSE values less than $10 \%$.

The CFD model developed for the non-tubular heater enables the extension of the correlations outside the range of the experimental data.

It also enables the analysis of variables whose measurement is practically unrealizable. In particular, it has been possible to analyse the coherence of the wall temperature values measured at a particular position and calculate in different flow conditions the heat exchanged through the non-tubular geometry, in whose walls the complex temperature distribution produces effects similar to those caused by a thermal irreversibility.

With respect to pressure losses, a finer meshing is probably needed to reduce the differences between the simulations and the experimental data.

The analysis procedure based on previously developed semi-empirical equations and correlations has been used to estimate the expected values of indicated and brake power for engine operation under nominal conditions. For these conditions, the CFD model has enabled the estimation of the heat power supplied by the heater to the gas during a cycle, which has facilitated the calculation of efficiencies. This power is not very different from the one that results from applying the recently obtained correlation for the SOLO V160 engine, with very different geometrical characteristics, working gas and operating conditions. The CFD model has also been used to obtain a correlation of the heat per cycle supplied to the gas, which will have to be verified in subsequent works.

From the results, it can be deduced that the experimental engine with a non-tubular heater can develop an indicated power of $693 \mathrm{~W}$ at $888 \mathrm{rpm}$, with an indicated efficiency of $29.3 \%$ and a mechanical efficiency of $81.0 \%$, i.e. a brake efficiency close to $24 \%$, operating with air as the working fluid at $p_{m}=6.9 \mathrm{bar}, T_{w E}=600^{\circ} \mathrm{C}$ and $T_{w C}=60^{\circ} \mathrm{C}$, which exceed the operating targets set in the preliminary design stage.

In addition, the characteristic curves obtained for different values of mean pressure show engine speeds in the points of maximum indicated power and maximum efficiency which are coherent with trends observed in other engines.

\section{Author Contributions:}

This paper is a result of the collaboration of all of the co-authors. David García updated the previous correlations of the pressure drop and heat transfer in non-tubular heater, performed the analysis of the engine operation and drafted the manuscript. María-José Suárez developed the CFD model of the heater and implemented the simulations under the supervision of Eduardo Blanco. Jesús-Ignacio Prieto conceived the study and revised the final structure of the paper. All of the authors read and approved the final manuscript.

\section{Nomenclature}

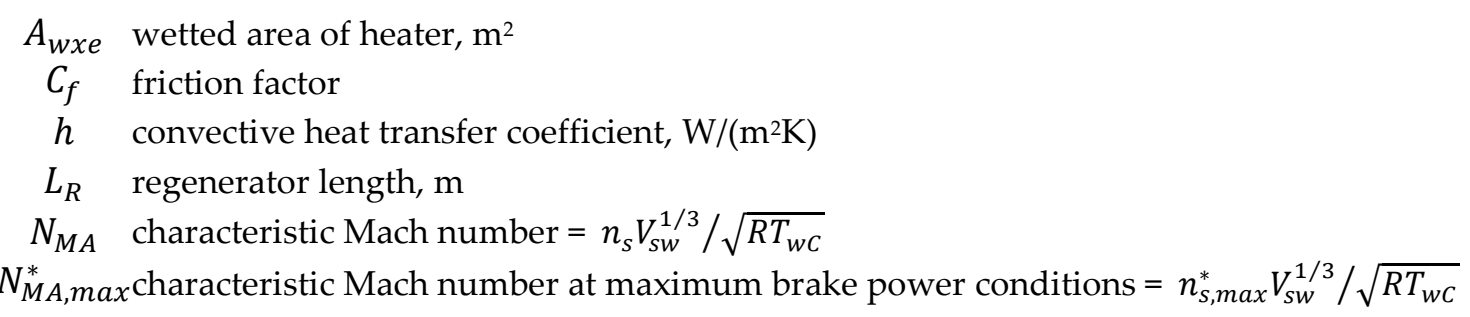


$N_{M A, \max }$ characteristic Mach number at maximum indicated power conditions $=n_{s, \max } V_{s w}^{1 / 3} / \sqrt{R T_{w C}}$

$N_{p} \quad$ characteristic pressure number $=p_{m} V_{s w}^{1 / 3} /\left(\mu \sqrt{R T_{w C}}\right)$

$N_{p r} \quad$ Prandtl number

$N_{r e}$ Reynolds number

$N_{s t} \quad$ Stanton number

$n_{s} \quad$ engine speed, rev/s

$n_{s, \text { max }}^{*}$ engine speed at maximum brake power, rev/s

$n_{s, \max }$ engine speed at maximum indicated power, rev/s

$\Delta p$ pressure loss across the heater, $\mathrm{Pa}$

$p_{m e}$ mean effective pressure, $\mathrm{Pa}$

$p_{m}$ mean pressure, $\mathrm{Pa}$

$P_{B, \max }$ maximum brake power, $\mathrm{W}$

$\dot{Q}_{E} \quad$ thermal power in the heater, $\mathrm{W}$

$R \quad$ specific gas constant, $\mathrm{J} /(\mathrm{kg} \cdot \mathrm{K})$

$R_{h R}$ regenerator hydraulic radius, $\mathrm{m}$

$\Delta T_{g} \quad$ variation in gas temperature across heater, $\mathrm{K}=T_{g o}-T_{g i}$

$T_{g}$ gas temperature, $\mathrm{K}$

$T_{T C} \quad$ thermocouple temperature, $\mathrm{K}$

$T_{w} \quad$ wall temperature, $\mathrm{K}$

$T_{w C} \quad$ cooler wall temperature, $\mathrm{K}$

$T_{w E} \quad$ heater wall temperature, $\mathrm{K}$

$T_{w}^{*} \quad$ mean wall temperature in the outer circular surface of the heater, $\mathrm{K}$

$T_{w}^{* *}$ mean wall temperature in the surface in contact with the working fluid, $\mathrm{K}$

$\overline{T_{g}}$ mean gas temperature in heater, $\mathrm{K}=0.5\left(T_{g i}+T_{g o}\right)$

$V_{d x} \quad$ dead volume of space $\mathrm{x}, \mathrm{m}^{3}$

$V_{S W} \quad$ swept volume, $\mathrm{m}^{3}$

$\varepsilon \quad$ heater wall emissivity

$\gamma \quad$ adiabatic coefficient of working fluid

$\Phi \quad$ coefficient of lineal indicated power losses

$\mu \quad$ working fluid viscosity, $\mathrm{Pa} \cdot \mathrm{s}$

$\mu_{d x} \quad$ dimensionless dead volume of space $\mathrm{x}=V_{d x} / V_{s w}$

$\Psi \quad$ coefficient of quadratic indicated power losses

$\sigma_{0} \quad$ Stephan-Boltzmann constant $=5.67 \cdot 10^{-8} \mathrm{~W} /\left(\mathrm{m}^{2} \mathrm{~K}^{4}\right)$

$\tau$ temperature ratio $=T_{w C} / T_{w E}$

$\zeta_{B, \max }$ dimensionless brake power at maximum brake power conditions

$\zeta_{\text {ind }}$ dimensionless indicated power

$\zeta_{\text {ind,max }}$ dimensionless indicated power at maximum indicated power conditions

$\zeta_{0}$ quasi-static dimensionless work per cycle

409 Subscripts

$\exp$ experimental value

$i \quad$ inlet section

$o$ outlet section

sim CFD simulated value

\section{References}

412 [1] T. Li, D.W. Tang, Z. Li, J. Du, T. Zhou, Y. Jia, Development and test of a Stirling engine driven by waste gases for the micro-CHP system, Appl. Thermal Eng. 33-34 (2012) 119-123. 
[2] C. Ulloa, P. Eguía, J.L. Miguez, J. Porteiro, J.M. Pousada-Carballo, A. Cacabelos, Feasibility of using a Stirling engine-based micro-CHP to provide heat and electricity to a recreational sailing boat in different European ports, Appl. Thermal Eng. 59 (2013) 414-424.

[3] M. Renzi, C. Brandoni, Study and application of a regenerative Stirling cogeneration device based on biomass combustion, Appl. Thermal Eng. 67 (2014) 341-351.

[4] L. Mingxi, S. Yang, F. Fang, Combined cooling, heating and power systems: A survey. Renew. Sust. Energy Rev. 35 (2014) 1-22.

[5] H. Cho, A.D. Smith, P. Mago, Combined cooling, heating and power: A review of performance improvement and optimization. Appl. Energy 136 (2014) 168-185.

[6] H. Al Moussawi, F. Fardoun, H. Louahlia-Gualous, Review of tri-generation technologies: Design evaluation, optimization, decision-making, and selection approach. Energy Convers. Manag. 120 (2016) 157-196.

[7] J. Cockroft, N. Kelly, A compartive assesment of future heat and power sources for the UK domestic sector, Energy Convers. Manag. 47 (2006) 2349-2360.

[8] T. Mancini, P. Heller, B. Butler, B. Osborn, W. Schiel, V. Goldberg, R. Buck, R. Diver, C. Andraka, J. Moreno, Dish-Stirling Systems: An Overview of Development and Status. J. Solar Energy Eng. 125 (2003) 135-151.

[9] A. Organ, Intimate thermodynamic design of the Stirling engine gas circuit without the computer, Proc. Inst. Mech. Eng. C J. Mech. Eng. Sci. 205 (1991) 421-430.

[10] J.I. Prieto, Discussion on intimate thermodynamic design of the Stirling engine gas circuit without the computer, Proc. Inst. Mech. Eng. C J. Mech. Eng. Sci. 206 (1992) 219-220.

[11] A. Organ, Thermodynamics and Gas Dynamics of the Stirling Cycle Machine; Cambridge University Press, Cambridge, 1992.

[12] J.I. Prieto, R. Díaz. Isothermal simulation with decoupled losses for kinematic Stirling engine design. JSME Int. J. 36(4) (1993) 697-10.

[13] A. Organ, Stirling Engine Thermodynamic Design without the Computer, Regenerative Thermal Machines (mRT), Cambridge, 1993.

[14] J.I. Prieto, J Fano, R. Díaz, M.A. González, Application of discriminated dimensional analysis to the kinematic Stirling engine, Proc. Inst. Mech. Eng. C J. Mech. Eng. Sci. 208 (1994) 347-353.

[15] J.I. Prieto, M.A. González, C. González, J Fano, A new equation representing the performance of kinematic Stirling engines, Proc. Inst. Mech. Eng. C J. Mech. Eng. Sci. 214 (2000) 449-464.

[16] J.I. Prieto, Discussion on Analysis of the Working Process and Mechanical Losses in a Stirling Engine for a Solar Power Unit. J. Solar Energy Eng. (Trans. ASME). 122 (2000) 207-208.

[17] J.I. Prieto, A.B. Stefanofskiy, Dimensional analysis of leakage and mechanical power losses of kinematic Stirling engines, Proc. Inst. Mech. Eng. C J. Mech. Eng. Sci. 217 (2003) 917-934.

[18] J.I. Prieto, Discussion on Performance of Stirling Engines (Arranging Method of Experimental Results and Performance Prediction). JSME Int. J. B. 46(1) (2003) 214-218.

[19] J.I. Prieto, M.A. González, C. González, J Fano, Notes on the scaling process of Stirling machines. In: Proceedings of the 7th International Stirling Conference on Stirling Cycle Machines, Tokyo, JP; 1995: 259_ 64.

[20] J.I. Prieto, J Fano, C. González, M.A. González, R. Díaz, Preliminary design of the kinematic Stirling engine using dynamic similarity and quasi-static simulation, Proc. Inst. Mech. Eng. C J. Mech. Eng. Sci. 211 (1997) 229-238.

[21] J.I. Prieto, Discussion on Stirling's air engine - a thermodynamic appreciation, Proc. Inst. Mech. Eng. C J. Mech. Eng. Sci. 216 (2002) 212-213.

[22] J.I. Prieto, Performance Characteristics and Preliminary Design Criteria of Stirling Engines. Hydrogen and Other Technologies Vol. 11, 2015, in: J.N. Govil, R. Prasad, S. Sivakumar, U.C. Sharma (Eds.), Energy Science \& Technology (12 vol.), Studium Press LLC, Houston, TX, USA, 2015, pp. 439-480.

[23] F. Sala, C. Invernizzi, D. García, M.A. González, J.I. Prieto, Preliminary design criteria of Stirling engines taking into account real gas effects, Appl. Thermal Eng. 89 (2015) 978-989.

[24] D. García, M.A. González, J.I. Prieto, S. Herrero, S. López, I. Mesonero, C. Villasante, Characterization of the power and efficiency of Stirling engine subsystems, Appl. Energy 121 (2014) 51-63. 
[25] I. Mesonero, S. López, F. García-Granados, F.J. Jiménez-Espadafor, D. García, J.I. Prieto, Indirect characterisation of indicated power in Stirling engines through brake power measurements, Appl. Thermal Eng. 100 (2016) 961-971.

[26] D. García, J.I. Prieto, A non-tubular Stirling engine heater for a micro solar power unit, Renew. Energy 46 (2012) 127-136.

[27] W. McAdams, Transmisión de calor, McGraw Hill, México, 1978.

[28] B.E. Launder, D.B. Spalding, The numerical computation of turbulent flows, Comput. Methods Appl. Mech. Eng. 3 (1974) 269-289.

[29] C.M. Hargreaves, The Philips Stirling Engine, Elsevier Science Publishers B.V., Amsterdam, 1991. 